\title{
TAYLOR RULES IN A LIMITED \\ PARTICIPATION MODEL
}

\author{
Lawrence J. Christiano \\ Christopher J. Gust \\ Working Paper 7017 \\ http://www.nber.org/papers/w7017 \\ NATIONAL BUREAU OF ECONOMIC RESEARCH \\ 1050 Massachusetts Avenue \\ Cambridge, MA 02138 \\ March 1999
}

Portions of this document are reprinted, with the permission of the University of Chicago Press, from a comments by us that is forthcoming in Taylor (1999a). Christiano is grateful to the National Science Foundation for a grant to the National Bureau of Economic Research. The views expressed in this paper are those of the authors and do not reflect those of the National Bureau of Economic Research.

(1999 by Lawrence J. Christiano and Christopher J. Gust. All rights reserved. Short sections of text, not to exceed two paragraphs, may be quoted without explicit permission provided that full credit, including

${ }^{(0)}$ notice, is given to the source. 
Taylor Rules in a Limited Participation Model

Lawrence J. Christiano and Christopher J. Gust

NBER Working Paper No. 7017

March 1999

JEL No. E1, E4, E52, E58

\section{ABSTRACT}

We use the limited participation model of money as a laboratory for studying the operating characteristics of Taylor rules for setting the rate of interest. Rules are evaluated according to their ability to protect the economy from bad outcomes such as the burst of inflation observed in the 1970s. Based on our analysis, we argue for a rule which: (i) raises the nominal interest rate more than one-for-one with a rise in inflation; and (ii) does not change the interest rate in response to a change in output relative to trend.

Lawrence J. Christiano

Department of Economics

Northwestern University

2003 Sheridan Road

Evanston, IL 60208-2600

and NBER

lchrist@merle.acns.nwu.edu
Christopher J. Gust

International Finance Division

Federal Reserve Board of Governors

Washington, D.C. 20551 


\section{Introduction and Overview}

Much research in monetary economics is stimulated by the burst of inflation experienced by a number of countries in the 1970s. This research addresses two questions: 'why did this costly failure of monetary policy occur?', and 'what can be done to prevent it from happening again?'

This introduction begins by briefly reviewing the evolution of thinking on these questions, from the focus on institutional reform in the 1980s, to the focus on the design of monetary policy rules more recently. We go on to discuss Taylor rules specifically, and why it is of interest to consider their operating characteristics in a limited participation model of money. We then summarize the results obtained when we do this. An implication of one of our results is that further progress on the analysis of monetary policy rules would benefit from addressing some of the issues of credibility considered in the earlier literature on institutional reform.

\subsection{Identifying Good Institutions}

The initial body of research addressing the two questions in the opening paragraph was stimulated by the seminal papers of Kydland and Prescott (1977) and Barro and Gordon (1983). This work suggested that there was an inflation bias inherent in monetary institutions and that some sort of institutional reform was required to prevent a recurrence of 1970s-style inflation. Examples of such institutional reform include legislative changes that focus a central bank's mission more sharply on inflation and that grant central banks more independence from the rest of the government. Barro and Gordon's analysis led to the prediction that, absent such reform, inflation would move up and down as the incentives to inflate moved up and down. To operationalize the theory, they made the assumption that the central bank's incentive to inflate is measured by the natural rate of unemployment. However, the Barro and Gordon theory lost some of its appeal in the two decades since they wrote their paper, when the incoming evidence appeared to contradict it. ${ }^{1}$ In the United States, a major, persistent drop in the rate of inflation occurred starting in 1980, about three years before the unemployment rate started to come down. In Europe and other countries, the incentive to inflate stood at a post-war high in the 1980s and 1990s because the unemployment rate was so high, and yet

\footnotetext{
${ }^{1}$ Evidence that does support the Kydland and Prescott (1977) - Barro and Gordon (1983) idea concerns the relationship between inflation and central bank independence. See, for example, the survey in Blanchard (1997, p. 55).
} 
inflation was very low. ${ }^{2}$ Both sets of observations are puzzling from the Barro and Gordon perspective, particularly because they were not preceded by significant, formal institutional reform. ${ }^{3}$

\subsection{Identifying Good Policy Rules}

Alternative approaches to the two questions driving this literature were developed. These place less emphasis on issues of commitment and on the notion that there is an inflation bias in modern monetary institutions. To explain this, the concept of a monetary policy 'rule' is useful. This specifies how the monetary authority varies the instruments at its command as a function of the state of the economy. The recent research focuses on identifying simple monetary policy rules that will reduce the likelihood of a recurrence of a 1970s style inflation outbreak. The underlying vision is that the poor economic outcomes of the 1970s were a consequence of the poor monetary policy rule in place at that time. The notion that improvements in our understanding of the economy that have occurred since then, arising both from conceptual advances and from increased data, put us in a position to design a better rule now. ${ }^{4}$

\footnotetext{
${ }^{2}$ See Christiano and Fitzgerald (1999) and Friedman and Kuttner (1996) for an elaboration on these observations.

${ }^{3}$ Various modifications of the Barro and Gordon approach can potentially reconcile the observations on inflation and unemployment with the theory. For example, one can posit that there is variation over time in policymaker preferences (see Ball (1995), Cukierman and Meltzer (1986), or Rogoff (1985)). Alternatively, by adopting a version of their theory in which the equilibrium variables are a function of the history of past government actions, it is possible to have equilibria in which central banks are 'pushed' into supplying more or less inflation in response to movements in variables other than the natural rate of unemployment (see Chari, Christiano and Eichenbaum (1998).) This can potentially account for the puzzling observations just cited. We consider this below.

${ }^{4}$ For a somewhat pessimistic assessment of the outlook for this approach, see Sargent (1999). He constructs a variant of the Kydland-Prescott/Barro-Gordon model in which the policymaker modifies its views about the structure of the economy as new data come in. As these views evolve, the policymaker adjusts its monetary policy rule. In Sargent's example, this process does not converge. It simply leads to an endless repetition of inflation take-off's like that observed in the 1970s, followed by inflation collapses. Sargent's example is important because it articulates clearly a potential pitfall associated with the design of monetary policy rules. Still, the details of his model are rejected in the sense that it is not able to account for duration of the high inflation in the 1970s. The reason is that the policy maker in Sargent's model, when confronted with the simultaneous rise in inflation and unemployment observed in the early 1970s, would have inferred that high inflation is not a productive way to reduce unemployment. According to
} 
In the quest for good monetary policy rules, rules for setting the interest rate have taken a particularly prominent role. Such rules are called 'Taylor rules' after John Taylor, who has played an important role in popularizing this research. The work has attracted so much attention in part because the interest rate is what central bankers view themselves as controlling. As a result, the research on interest rate rules has substantial potential practical relevance. Although this research is still fairly new, a consensus has already begun to emerge. To explain this, consider the following typical Taylor rule

$$
r_{t}=c+\rho r_{t-1}+\alpha \pi_{t}+\beta y_{t}
$$

where $\pi_{t}$ is the annualized rate of inflation, $r_{t}$ is the annualized Federal Funds rate and $y_{t}$ is the log deviation of output from trend. The emerging consensus is that a Taylor rule characterized by an aggressive response of the interest rate to high inflation and high output is likely to yield good results. ${ }^{5}$ For example, Taylor (1999) urges the implementation of a rule with $\rho=0, \beta=1$ and $\alpha=1.5$.

\subsection{The Limited Participation Model as a Laboratory}

The strategy of the existing literature evaluates monetary policy rules by studying their operating characteristics in quantitative, economic models. For the most part, the models used in this literature are sticky price, rational expectations versions of the IS-LM model. ${ }^{6}$ The question naturally arises: are the existing results robust to alternative, plausible models? We investigate this in the context of one such model. In particular, we investigate the performance of Taylor rules in a simple limited participation model recently studied by Christiano, Eichenbaum and Evans (1998) (CCE). ${ }^{7}$ The mechanisms in this model differ from those in the existing literature. In particular, the friction which generates monetary nonneutrality is a credit market friction, not stickiness in price setting. In addition, the channel from expected inflation to output in this model differs from what it

Sargent's model, the policymaker's reaction to this discovery would have been to keep inflation low. See Sargent's chapter 9 for a further discussion.

${ }^{5}$ See the papers in Taylor (1999a). See also Clarida, Gali and Gertler (1997) and King and Kerr (1996).

${ }^{6}$ When researchers adopt models not in this paradigm, they often get different results. See, for example, Benhabib, Schmitt-Grohe and Uribe (1998).

${ }^{7}$ For a comparison of the empirical performance of sticky price versus limited participation models, see Christiano, Eichenbaum and Evans (1997). 
is in the sticky price, rational expectations version of the IS-LM model. Since the source of monetary frictions and the channels from expected inflation to output are not yet well understood, we view our analysis as providing a useful robustness check on the existing literature.

In evaluating a particular parameterization of the Taylor rule, we focus primarily on its ability to rule out bad outcomes. ${ }^{8}$ In particular, we want to ensure that the monetary policy rule is not itself a source of welfare-reducing instability for the economy. ${ }^{9}$ This can happen for at least two reasons: (i) the rule may enable expectations of inflation to become self fulfilling, a situation that can occur when the steady state equilibrium of the nonstochastic version of the economy is 'indeterminate' and (ii) the rule may cause the economy to react explosively to shocks.

\subsection{Our Results}

Three results are reported below that we wish to emphasize here. First, aggressiveness in a Taylor rule is a good idea, but only in response to inflation. Aggressiveness in the response to deviations in output from trend is a bad idea in our model, and can produce welfare-reducing volatility of the kind cited in (i) and (ii) in the previous paragraph. For example, we find that Taylor's recommended values for $\alpha, \rho, \beta$ places too much weight on output, and result in explosiveness. ${ }^{10}$ Second, when we incorporate the monetary policy rule estimated by Clarida, Gali and Gertler (1997) to have been followed by the US Federal Reserve in the 1970s into our model, we find that the model exhibits equilibrium indeterminacy. As a result, our model is able to articulate the view that the burst of high inflation in

\footnotetext{
${ }^{8}$ We do not seek to identify policy rule parameter values that optimize utility in our model, and we make no attempt to compare the performance of Taylor rules with the unconstrained optimal monetary policy. In our experience, first-order welfare gains are to be had by avoiding the 'bad outcomes' listed next in the text. Once these outcomes have been avoided, there is relatively less to be gained from moving to the globally optimal specification. This is consistent with findings reported in Rotemberg and Woodford (1999), who display a model in which the welfare function is relatively insensitive to alternative specifications of interest rate rules, as long as only parameter values in the region of equilibrium determinacy are considered.

${ }^{9}$ Other research that adopts this perspective on the design of monetary policy rules includes Carlstrom and Fuerst (1998, 1999) and Benhabib, Schmitt-Grohe and Uribe (1998).

${ }^{10}$ For another model with this property, see Isard, Laxton and Eliasson (1999).
} 
the 1970 s was due to higher expectations of inflation. ${ }^{11}$ According to the model, these expectations were translated into higher actual inflation because the policy rule implemented in the 1970s was insufficiently aggressive with respect to inflation. In this respect, our result is similar to the one reported for the sticky price, rational expectations version of the IS-LM model considered by Clarida, Gali and Gertler (1997). Still, our result does differ from theirs in one potentially important respect. In our model, a rise in inflation expectations that is self-fulfilling acts to weaken the economy. In a model like that of Clarida, Gali and Gertler (1997), such a rise in inflation expectations drives output up. This distinction between these two classes of models may provide a way to discriminate between them, since the 1970s are thought to be a period when output was low relative to trend.

The basic intuition underlying these different implications of our model and versions of the standard IS-LM model is simple. The latter emphasize that higher anticipated inflation leads to a reduction in the real rate of interest, which in turn results in a rise in output and actual inflation by stimulating the investment component of aggregate demand. ${ }^{12}$ If the central bank adopts a tight money policy every time output and/or inflation is high, this chain of causation from expected inflation to actual inflation is cut. Thus, a high $\alpha$ and/or a high $\beta$ eliminates equilibria in these models in which high inflation is self-fulfilling.

Now consider our model. Here, higher anticipated inflation induces households to substitute out of cash deposits in the financial sector and towards the purchase of goods. The resulting shortfall of cash in the financial sector puts upward pressure on the nominal rate of interest. If $\alpha$ in the central bank's policy rule is small, it has to inject liquidity into financial markets in order to prevent a large rise in the rate of interest. This expansion of liquidity would produce the increase in inflation that people anticipated. This is the intuition underlying our finding that a small value of $\alpha$ increases the likelihood that expectations of inflation can

\footnotetext{
${ }^{11}$ This is a view that is also articulated in Chari, Christiano and Eichenbaum (1998) and Clarida, Gali and Gertler (1997).

${ }^{12}$ The basic logic can be illustrated using a textbook Aggregate Supply-Aggregate Demand diagram, with price on the vertical axis and output on the horizontal. In the usual way, a fall in expected inflation shifts Aggregate Demand to the right. Prices rise as the economy moves up along the Aggregate Supply curve. The resulting rise in price corresponds an actual rise in inflation. This chain linking expected inflation to actual inflation is broken if the authorities shift the Aggregate Demand Curve to the left whenever they see output or inflation rising. High values of $\alpha$ and $\beta$ do just that.
} 
be self-fulfilling. Similarly, a large value of $\alpha$ reduces the likelihood that this type of equilibrium could exist.

The previous intuition also shows why a large value of $\beta$ can actually increase the likelihood that inflation expectations are self-fulfilling in our model. That is because the rise in the interest rate that occurs with a rise in inflation under the Fed's policy rule also produces a reduction in output. With a large $\beta$, that fall in output operates to offset the Fed's policy of raising the interest rate when $\alpha>0$. In effect, raising $\beta$ cancels out the indeterminacy-fighting properties of a high value of $\alpha$.

Our third and final result that deserves emphasis is the following. Our analysis suggests that the literature on monetary policy rules may have been too quick to abandon the issues of commitment raised by the analysis of Kydland and Prescott (1977) and Barro and Gordon (1983). Our results suggest that a Taylor rule that is sufficiently aggressive to inoculate the economy against a 1970s style inflation outburst may lack credibility because there is a strong - perhaps irresistible incentive to deviate from it. We computed an example in which a benevolent central bank has an incentive to deviate from such a rule when there is a supply shock which drives prices up and output down simultaneously. In the example, the increased welfare gains from deviating to a $k \%$ rule at that time are the equivalent of about $0.3 \%$ of consumption, forever. To get a sense of the magnitude of this, it corresponds roughly to the amount the federal government spends on the administration of justice, or on general science, space, and technology. ${ }^{13}$ This is a substantial amount, and may be difficult to resist for a central bank. A more complete analysis of the concerns raised in this example requires spelling out more clearly the details of the environment. This is beyond the scope of our analysis. ${ }^{14}$

\footnotetext{
${ }^{13}$ The preliminary estimate for 1997 of consumption of nondurable goods and services in the 1998 Economic Report of the President is $\$ 4.8$ trillion, so that $0.3 \%$ of this is $\$ 16$ billion. The federal expenditures in fiscal year 1997 on general science, space, and technology was $\$ 17$ billion, an on the administration of justice it was $\$ 20$ billion.

${ }^{14}$ Rotemberg and Woodford have pointed out to us in private conversation that a sticky price model may not suffer from the sort of credibility problem emphasized here. In a sticky price model, there is a tendency for output to fall by less than the efficient amount, after a bad technology shock. According to this model, implementing a tight monetary policy at such a time might actually improve the welfare of private agents.
} 


\subsection{Rules and Credibility}

These results on credibility highlight a different possible answer to the two questions posed in the first paragraph. It may be that the problem in the 1970s was not lack of knowledge that a higher value of $\alpha$ might have prevented the inflation take off. Instead, reasoning as in Chari, Christiano and Eichenbaum (1998), that episode may have reflected a weakness in monetary policy institutions, which simply could not resist accommodating higher inflation expectations in a faltering economy.

That these concerns may be of more than academic interest is suggested by the statements on inflation by Arthur Burns, who was chairman of the Federal Reserve in the 1970s. These suggest that his failure to raise interest rates in line with the dictates of a more aggressive Taylor rule did not reflect ignorance about the connection between money and inflation. He claimed that, instead, it was his fear of the social consequences of such an action that prevented him from implementing a high interest rate policy. ${ }^{15}$ Thus, both history and theory suggest that credibility issues should also be considered when designing monetary policy rules.

The next section briefly describes our model. Results are presented in the following section. We close with a brief conclusion.

\section{Model}

In this section, we describe the model used in our analysis and we present some empirical evidence in its favor.

\footnotetext{
${ }^{15}$ An excerpt from a speech by Arthur Burns in 1977 summarizes views that he repeated often during his tenure as chairman of the Federal Reserve: "We well know-as do many others-that if the Federal Reserve stopped creating new money, or if this activity were slowed drastically, inflation would soon either come to an end or be substantially checked. Unfortunately, knowing that truth is not as helpful as one might suppose. The catch is that nowadays there are tremendous nonmonetary pressures in our economy that are tending to drive costs and prices higher....If the Federal Reserve then sought to create a monetary environment that seriously fell short of accommodating the nonmonetary pressures that have become characteristic of our times, severe stresses could be quickly produced in our economy. The inflation rate would probably fall in the process but so, too, would production, jobs, and profits. The tactics and strategy of the Federal Reserve System-as of any central bank-must be attuned to these realities.' For additional discussion of Burns' (1978) speeches, see Chari, Christiano and Eichenbaum (1998).
} 
We examine the operating characteristics in our model of the following three variants on (1.1):

$$
\begin{gathered}
r_{t}=c+\rho r_{t-1}+\alpha E_{t} \pi_{t+1}+\beta y_{t}, \quad \text { (Clarida-Gali-Gertler) } \\
r_{t}=c+\rho r_{t-1}+\alpha \pi_{t}+\beta y_{t}, \quad \text { (Generalized Taylor) } \\
r_{t}=c+\rho r_{t-1}+\alpha \tilde{\pi}_{t-1}+\beta y_{t-1}, \quad \text { (Lagged Taylor) }
\end{gathered}
$$

As before, $r_{t}$ is the (annualized) nominal rate of interest that extends from the beginning of quarter $t$ to the end of quarter $t$. Also, $\pi_{t}=\log \left(P_{t}\right)-\log \left(P_{t-1}\right)$, $\tilde{\pi}_{t}=\log \left(P_{t}\right)-\log \left(P_{t-4}\right)$, and $y_{t}=\log \left(Y_{t}\right)$, after a trend has been removed. We refer to the above as the Clarida, Gali, and Gertler (1997) (CGG), the Generalized Taylor (GT) and Lagged Taylor (LT) policy rules, respectively.

We study the performance of these three rules in the CEE model. A detailed discussion of the model appears in CEE, and so we describe it only very briefly here. Apart from two modifications, it is basically a standard limited participation model. One modification is that, in addition to having a technology shock, it also has a money demand shock. Traditionally, an important rationale for adopting an interest rate targeting rule was to eliminate the effects of money demand shocks from the real economy (see, for example, Poole (1970).) So, if anything, including them in the analysis should bias the results in favor of the interest rate targeting rule. A second difference is that, although there is still a monetary authority on the sidelines transferring cash into and out of the financial system in our model economy, those transfers are endogenous when the monetary authority conducts its operations with the objective of supporting an interest rate targeting rule.

The representative household begins period $t$ with the economy's stock of money, $M_{t}$, and then proceeds to divide it between $Q_{t}$ dollars allocated to the purchase of goods, and $M_{t}-Q_{t}$ dollars allocated to the financial intermediary. It faces the following cash constraint in the goods market:

$$
Q_{t}+W_{t} L_{t} \geq P_{t}\left(C_{t}+I_{t}\right)
$$

where $I_{t}$ denotes investment, $C_{t}$ denotes consumption, $L_{t}$ denotes hours worked, and $W_{t}$ and $P_{t}$ denote the wage rate and price level. The household owns the stock of capital, and it has the standard capital accumulation technology:

$$
K_{t+1}=I_{t}+(1-0.02) K_{t} .
$$


The household's assets accumulate according to the following expression:

$$
M_{t+1}=Q_{t}+W_{t} L_{t}-P_{t}\left(C_{t}+I_{t}\right)+R_{t}\left(M_{t}-Q_{t}+X_{t}\right)+D_{t}+r_{k t} K_{t},
$$

where $X_{t}$ is a date $t$ monetary injection by the central bank and $R_{t}$ denotes the gross quarterly rate of return on household deposits with the financial intermediary. ${ }^{16}$ Also, $D_{t}$ denotes household profits, treated as lump sum transfers, and $r_{k t}$ is the rental rate on capital. An implication of this setup is that the household's date $t$ earnings of rent on capital cannot be spent until the following period, while its date $t$ wage earnings can be spent in the same period. As a result, inflation acts like a tax on investment. The household's date $t$ decision about $Q_{t}$ must be made before the date $t$ realization of the shocks, while all other decisions are made afterward. This assumption is what guarantees that when a surprise monetary injection occurs, the equilibrium rate of interest falls, and output and employment rise. To assure that these effects are persistent, we introduce an adjustment cost in changing $Q_{t}, H_{t}=H\left(\frac{Q_{t}}{Q_{t-1}}\right)$, where $H_{t}$ is in units of time, and $H$ is an increasing function. ${ }^{17}$ The household's problem at time 0 is to choose contingency plans for $C_{t}, I_{t}, Q_{t}, M_{t+1}, L_{t}, K_{t+1}, t=0, \ldots, \infty$ to maximize

$$
E_{0} \sum_{t=0}^{\infty}\left(1.03^{-.25}\right)^{t} U\left(C_{t}, L_{t}, H_{t}\right), U(C, L, H)=\log \left[C-\psi_{0} \frac{(L+H)^{(1+\psi)}}{1+\psi}\right] \text {, }
$$

subject to the information, cash, asset accumulation and other constraints. Here, $\psi=1 / 2.5$ and $\psi_{0}$ is selected so that $L_{t}=1$ in nonstochastic steady state.

Firms must finance $J_{t}$ of the wage bill by borrowing cash in advance from the financial intermediary, and $1-J_{t}$ can be financed out of current receipts. The random variable, $J_{t}$, is our money demand shock, and it is assumed to have the following distribution:

$$
\log \left(J_{t}\right)=0.95 \log \left(J_{t-1}\right)+\varepsilon_{J, t},
$$

\footnotetext{
${ }^{16}$ We have $r_{t}=4\left(R_{t}-1\right)$.

${ }^{17}$ To assure that the interest rate effect is persistent, we introduce a cost of adjusting $Q_{t}$ :

$$
H\left(\frac{Q_{t}}{Q_{t-1}}\right)=d\left\{\exp \left[c\left(\frac{Q_{t}}{Q_{t-1}}-1-x\right)\right]+\exp \left[-c\left(\frac{Q_{t}}{Q_{t-1}}-1-x\right)\right]-2\right\}
$$
}

where $x$ denotes the average rate of money growth. We set $d=c=2$ and $x=0.01$. 
where $\varepsilon_{J, t}$ has mean zero and standard deviation 0.01 . All of the rental payments on capital can be financed out of current receipts. This leads to the following first order conditions for labor and capital:

$$
\frac{W_{t}\left[R_{t} J_{t}+1-J_{t}\right]}{P_{t}}=\frac{f_{L, t}}{\mu}, \frac{r_{k t}}{P_{t}}=\frac{f_{K, t}}{\mu},
$$

where $\mu=1.4$ is the markup of price over marginal cost, reflecting the existence of market power. Also, $f_{i, t}$ represents the marginal product of factor $i, i=L, K$, and

$$
f\left(K_{t}, L_{t}, v_{t}\right)=\exp \left(v_{t}\right) K_{t}^{0.36} L_{t}^{0.64}
$$

where

$$
v_{t}=0.95 v_{t-1}+\varepsilon_{v, t},
$$

and $\varepsilon_{v, t}$ has mean zero and standard deviation 0.01 .

Finally, we specify monetary policy in four ways. In the first, money growth is purely exogenous, and has the following second order moving average form:

$$
x_{t}=x+0.08 \varepsilon_{t}+0.26 \varepsilon_{t-1}+0.11 \varepsilon_{t-2},
$$

where $\varepsilon_{t}$ is a mean zero, serially uncorrelated shock to monetary policy and $x=0.01$. This representation is Christiano, Eichenbaum and Evans (1998)'s estimate of the dynamic response of M1 growth to a monetary policy shock, after abstracting from the effects of all other shocks on monetary policy. Other representations of monetary policy analyzed here include the CGG, the GT and the LT rules presented above. In these cases, the response of $x_{t}$ to nonmonetary shocks is endogenous, although we preserve the assumption throughout that $E x_{t}=x$.

Figure 1 presents the dynamic response of the model's variables to an $\varepsilon_{t}$ shock in period 2. The percent deviation of the stock of money from its unshocked growth path is displayed in panel c. The magnitude of the shock was chosen so that the money stock is eventually up by 1 percent. Panels $a, b$ and $\mathrm{f}$ indicate that the impact effect on output of the monetary policy shock is so great that the price response is nil. Afterward, the price level rises slowly, and does not reach its steady state position until around one year later. The reasons for this sluggish response in the price level are discussed in detail in Christiano, Eichenbaum and Evans (1997). ${ }^{18}$ Next, note the hump-shaped responses of employment, output,

\footnotetext{
${ }^{18}$ The basic idea is as follows. A positive monetary injection has two effects: (i) it stimulates
} 
consumption and investment. Finally, there is a persistent fall in the interest rate. As emphasized in Christiano, Eichenbaum and Evans (1998), these patterns are all qualitatively consistent with the data. They support the notion that our model represents a useful laboratory for evaluating the operating characteristics of alternative monetary policy rules.

\section{Results}

This section presents our quantitative results. We first display the regions of the policy parameter space in which indeterminacy, determinacy and explosiveness occur. Loosely, determinacy corresponds to the case where equilibrium is (locally) unique, so that self-fulfilling inflation episodes are not possible. Indeterminacy corresponds to the case where such equilibria are possible. Explosiveness corresponds to the case in which a shock causes the economy to diverge permanently from its initial position. ${ }^{19}$ In the subsequent two subsections we report some calculations to illustrate the economic meaning of the indeterminacy and explosiveness findings. In addition, we discuss the credibility difficulties that may exist in implementing an interest rate rule in practice.

\subsection{Indeterminacy, Determinacy and Explosiveness}

Figures 2, 3 and 4 report regions of $\alpha, \beta$ where equilibrium is determinate (white), indeterminate (grey) and explosive (black), for $\rho=0.0,0.5,1.5$. The results are for the CGG, GT and LT rules, respectively.

We begin with a discussion of the results for the CGG rule, displayed in Figure 2. Consider the case, $\rho=0$, first. We find that when $\beta=0$, then determinacy requires $\alpha \geq \gamma$, where $\gamma$ is a number just below unity. ${ }^{20}$ This is analogous to findings reported in Kerr and King (1996) for the IS-LM model (see also CGG). In that model, the value of $\gamma$ where the economy switches between determinacy and

demand by putting more cash in the hands of households and (ii) it stimulates supply by reducing the rate of interest. The effect of (i) alone is to increase the price level. The effect of (ii) is to decrease the price level. If these supply and demand effects triggered by a monetary shock roughly cancel, there is only a small effect on the price level.

${ }^{19}$ Technically, determinacy, indeterminacy and explosiveness correspond to the number of explosive eigenvalues in the model's reduced form, as in the analysis of Blanchard and Kahn (1980).

${ }^{20}$ Note from Figure 2a that determinacy also requires that $\alpha$ not be too large. 
indeterminacy is $\gamma=1$. Our results resemble those of Kerr and King (1996) and CGG in supporting the notion that an aggressive response to expected inflation reduces the likelihood of indeterminacy. In contrast to CGG, however, we find that the likelihood of indeterminacy and explosiveness increase with $\beta$. The intuition for the former result was discussed in the introduction.

Now consider the case $\rho=0.5$. When $\beta=0$, then determinacy requires $\alpha \geq \gamma$, where $\gamma$ is a number just below 0.5. This result, and others not reported, are consistent with the notion that the condition for determinacy is similar to what it was in the case of $\rho=0$, as long as it is placed on $\alpha /(1-\rho)$, and not $\alpha$. That is, in several quantitative experiments we found that with $\beta=0$ and for $0<\rho<1$, determinacy requires $\alpha /(1-\rho)>\gamma$, where $\gamma$ is slightly below unity. Interestingly, $\alpha /(1-\rho)$ corresponds to the long run cumulative impact on the interest rate of a one-time increase in expected inflation. ${ }^{21}$ This suggests that what is important, in guaranteeing equilibrium determinacy, is that the cumulative effect over time of an increase in expected inflation be greater than unity. The precise timing of the response of the interest rise to an increase in inflation matters less. Note also that, like in the $\rho=0$ case, raising $\beta$ increases the likelihood of indeterminacy or explosiveness.

Finally, consider the case $\rho=1.5$. As is to be expected from the $\rho=0.5$ result, the range of $\alpha$ 's which generate determinacy is larger here. As in the other cases, increasing $\beta$ raises the likelihood of indeterminacy or explosiveness.

Now consider the results reported in Figure 3 for the GT rule. Taylor (1999) suggests that a good parameterization for (1.1) is $\rho=0, \alpha=1.5$ and $\beta=1$. Interestingly, Figure 3 indicates that, for our model, this parameterization lies in the explosiveness region. Thus, our model indicates that the economy would perform very poorly with this parameterization of the policy rule. According to the results in Rotemberg and Woodford (1999), when $\rho=0, \alpha>0$, then increasing $\beta$ raises the likelihood of equilibrium determinacy. In our model, this is not the case. Either we enter the explosiveness region for large $\beta$, or we enter the region of indeterminacy. Interestingly, as $\rho$ increases, the region of determinacy expands.

The results in Figure 4 for the LT policy rule resemble those in Figure 3. The preferred parameterization of Rotemberg and Woodford (1999), $\alpha=1.27, \beta=$ 0.08 and $\rho=1.13$ lies in the determinacy region for our model, if we extrapolate

\footnotetext{
${ }^{21}$ Thus, suppose there is a one-time pulse of magnitude unity in $E_{t} \pi_{t+1}$. The impact effect on $r_{t}$ is $\alpha$. The lag one effect is $\alpha \rho$, and the lag $i$ effect is $\alpha \rho^{i}$, for $i=1,2,3, \ldots$. The sum of these effects, as long as $|\rho|<1$, is $\alpha /(1-\rho)$.
} 
between the $\rho=0.5$ and $\rho=1.5$ graphs in Figure 4. A notable feature of the LT policy rule is that with $\rho$ large, the determinacy region is reasonably large and resembles the determinacy region for the GT rule.

To summarize, an aggressive response to inflation (or, expected inflation) increases the likelihood of determinacy. However, a more aggressive response to output has the opposite effect in our model. In addition, our results support the notion that choosing a high value of $\rho$ increases the likelihood of determinacy. Finally, the CGG rule appears to have the smallest region of determinacy.

\subsection{Illustrating Indeterminacy}

We report some calculations to illustrate what can happen when there is indeterminacy. To this end, we worked with two versions of the CGG rule. The first is useful for establishing a benchmark, and uses a version of the CGG rule for which there is a locally unique equilibrium, $(\rho=0.66, \beta=0.16, \alpha=0.61)$. The second uses a version, $(\rho=0.66, \beta=0.16, \alpha=0.32)$, of the CGG rule for which there is equilibrium indeterminacy. We refer to the first rule as the stable CGG rule and to the second as the unstable CGG rule. We consider the dynamic response of the variables in our model economy to a one standard deviation innovation in $J_{t}$ in period 2 .

Figure 5 displays the results for economy operating under a $k \%$ money growth rule (dotted line) and under the stable CGG rule. Note that under the $k \%$ rule, the results are what one might expect from a positive shock to money demand: interest rates rise for a while and inflation, output, employment, consumption and investment drop. Now consider the economy's response to the money demand shock under the stable CGG rule. As one might expect, this monetary policy fully insulates the economy from the effects of the money demand shock. Figure $5 \mathrm{c}$ indicates that this result is brought about by increasing the money stock. Not surprisingly, the present discounted utility of agents in the economy operating under the stable CGG rule, 74.092, is higher than it is in the economy operating under the $k \%$ rule, 74.036 . These present discounted values are computed under the assumption that the money demand shock takes on its mean value in the initial period, and the capital stock is at its nonstochastic steady-state level.

Now consider the results in Figure 6, which displays the response of the model variables to a money demand shock in two equilibria associated with the unstable CGG policy rule. In equilibrium \#2 (see the dotted line), the economy responds 
in essentially the same way that it does under the stable CGG rule. Now consider equilibrium \#1 (the solid line). The money demand shock triggers an expectation of higher inflation. Seeing the inflation coming, the central bank raises interest rates immediately by only partially accommodating the increased money demand. ${ }^{22}$ In the following period households, anticipating higher inflation, shift funds out of the financial sector and towards consumption (Figure 6b shows that $Q_{t}$ rises, relative to its steady state path, in period 3). The central bank responds by only partially making up for this shortfall of funds available to the financial sector. This leads to a further rise in the interest rate and in the money supply. In this way, the money stock grows, and actual inflation occurs. Employment and output are reduced because of the high rate of interest. Investment falls a lot because the higher anticipated inflation acts as a tax on the return to investment. In addition, the rental rate on capital drops with the fall in employment.

The utility level associated with equilibrium \#1 is 73.825 and the utility level in equilibrium \#2 is 74.110. The utility numbers convey an interesting message. On the one hand, if the stable CGG rule is implemented, then agents enjoy higher utility than under the $k \%$ rule. On the other hand, if the unstable CGG policy rule is used, then it is possible that utility might be less than what it would be under the $k \%$ rule. In this sense, if there were any uncertainty over whether a given interest rate rule might produce indeterminacy, it might be viewed as less risky to simply adopt the $k \%$ rule. In a way, this is a dramatic finding, since the assumption that money demand shocks are the only disturbances impacting on the economy would normally guarantee the desirability of an interest rate rule like (1.1).

\subsection{Illustrating Explosiveness and Implementation Problems}

We now consider a version of our model driven only by technology shocks. We consider two versions of the LT policy rule. One adopts the preferred parameterization of Rotemberg and Woodford (1999): $\alpha=1.27, \beta=0.08, \rho=1.13$. The other adopts a version of this parameterization that is very close to the explosive region in which $\beta$ is assigned a value of unity. Figure 7 reports the response of the economy to a one standard deviation negative shock to technology under two

\footnotetext{
${ }^{22}$ This is difficult to see in Figure $6 c$ because of scale. Money growth in period 2 is nearly 6 percent, at an annual rate, in equilibrium 2. According to Figure 6g, this is enough to prevent a rise in the interest rate in that equilibrium. Money growth in period 2 of equilibrium \#1 is less, namely 5.5 percent, at an annual rate.
} 
specifications of monetary policy. In one, monetary policy is governed by a $k \%$ rule (see the dotted line), and in the other it is governed by the LT rule just described (see the solid line).

Consider first the $k \%$ rule. The technology shock drives up the price level, which remains high for a long period of time. Employment, investment, consumption and output drop. There is essentially no impact on the rate of interest. The present discounted value of utility in this equilibrium is 74.095. Consider by contrast the LT rule. The rise in inflation in the first period leads the central bank to cut back the money supply in the following period (recall, this policy rule looks back one period). This triggers a substantial rise in the interest rate, which in turn leads to an even greater fall in employment, output, consumption and investment than occurs under the $k \%$ rule. The present discounted value of utility in this equilibrium is 74.036. It is not surprising that in this case, the $k \%$ rule dominates the monetary policy rule in welfare terms, and in terms of the variability of output and inflation.

Now consider the operation of the nearly explosive policy rule, in Figure 8. With this rule, responses are much more persistent than under the previous rule. The response looks very much like a regime switch, with money growth and the interest rate shifting to a higher level for a long period of time. Given all the volatility in this equilibrium, it is not surprising that welfare is lower at 73.549.

These examples illustrate the practical difficulties that can arise in implementing an interest smoothing rule like (1.1). In a recession, when output and employment are already low, the rule may require tightening even further. The social cost of doing that may be such that the pressures to deviate may be irresistible. Numerical results to support this proposition were summarized in the introduction. ${ }^{23}$

\section{Conclusion}

One interpretation of the high inflation experience of the $1970 \mathrm{~s}$ is that it was the outcome of the Federal Reserve implementing a policy rule which permitted

\footnotetext{
${ }^{23}$ Clarida, Gali and Gertler (1997a) argue for a specification in which $y_{t}$ is the deviation from potential output, rather than from trend, as we do here. We suspect that if we replace $y_{t}$ in the Taylor rule with the deviation from potential, the credibility problem with our policy rule would be worse, for $\beta>0$. To see why, note that with $\beta\left(y_{t}-z_{t}\right)$, where $z_{t}$ is potential output, a fall in potential after a technology shock would act to raise the rate of interest even more.
} 
inflation expectations to be self-fulfilling. An important objective of monetary analysis is to design rules which will not allow bad outcomes like this to happen again. This paper studied the operating characteristics of Taylor rules in the context of a limited participation model of money. In this model, monetary nonneutrality arises from a particular friction in the household's portfolio decision. Equilibria in which expectations about inflation are self-fulfilling are eliminated when the Taylor rule responds aggressively to inflation and very little to output. A strong response to output risks destabilizing the economy. In this respect, the model's implications differ from those of standard sticky price models, which suggest that the possibility of self-fulfilling inflation expectations are ruled out when the Taylor rule responds aggressively both to inflation and output.

So, which model should be taken more seriously for purposes of designing monetary policy? We have pointed out that under a sticky price model, equilibria in which inflation expectations are self-fulfilling tend, other things the same, to be associated with high output and investment. The limited participation model has the opposite property. This suggests that the latter may have an easier time explaining the 1970s than the former, since this was a period when output and investment were generally low. If a more formal analysis turns out to support this possibility, then the policy implications of the limited participation model would need to be taken seriously.

But, suppose it is not so easy to determine which model, the sticky price model or the limited participation model, is closer to the truth? Robustness considerations suggest picking a rule which works well in either model. And, each model has the implication that bad outcomes are avoided by Taylor rules which

respond aggressively to inflation and not to output. So, we conclude that if a Taylor rule is to be adopted, then it should be of this type.

\section{References}

[1] Ball, Laurence, 1995, 'Time-Consistent Policy and Persistent Changes in Inflation,' Journal of Monetary Economics, vol. 36, no. 2, November, pages 329-50.

[2] Barro, Robert J., and David B. Gordon, 1983, 'A Positive Theory of Monetary Policy in a Natural Rate Model,' Journal of Political Economy 91 (August): 589-610. 
[3] Benhabib, Jess, Stephanie Schmitt-Grohe and Martin Uribe, 1998, 'Monetary Policy and Multiple Equilibria,' unpublished manuscript.

[4] Blanchard, Olivier, 1997, Macroeconomics, Prentice-Hall.

[5] Blanchard, Olivier, and Charles Kahn, 1980, 'The Solution of Linear Difference Models under Rational Expectations,' Econometrica, 48(5), pp. 1305-11.

[6] Burns, Arthur, 1978, 'Reflections of an Economic Policy Maker, Speeches and Congressional Statements: 1969-1978,' American Enterprise Institute for Public Policy Research, Washington D.C.

[7] Carlstrom, Charles T., and Timothy S. Fuerst, 1998, 'Real Indeterminacy under Inflation Rate Targeting,' manuscript.

[8] Carlstrom, Charles T., and Timothy S. Fuerst, 1999, 'Timing and Real Indeterminacy in Monetary Models,' unpublished manuscript.

[9] Chari, V.V., Lawrence J. Christiano, and Martin Eichenbaum, 1998, 'Expectation Traps and Discretion', Journal of Economic Theory.

[10] Christiano, Lawrence J., Martin Eichenbaum, and Charles Evans, 1997, 'Sticky Price and Limited Participation Models: A Comparison,' European Economic Review, Vol. 41, no. 6, pages 1201-1249.

[11] Christiano, Lawrence J., Martin Eichenbaum, and Charles Evans, 1998, 'Modeling Money,' National Bureau of Economic Research Working Paper 6371.

[12] Christiano, Lawrence J., and Terry Fitzgerald, 1999, 'Band Pass Filters,' unpublished manuscript.

[13] Clarida, Richard, Jordi Gali and Mark Gertler, 1997, 'Monetary Policy Rules and Macroeconomic Stability: Evidence and Some Theory,' manuscript, New York University.

[14] Clarida, Richard, Jordi Gali and Mark Gertler, 1997a, 'The Science of Monetary Policy,' manuscript, New York University. 
[15] Cukierman, Alex, and Allan Meltzer, 1986, 'A Theory of Ambiguity, Credibility, and Inflation under Discretion and Asymmetric Information,' Econometrica, vol. 54, no. 5, September, pages 1099-1128.

[16] Friedman, Benjamin M., and Kenneth N. Kuttner, 1996, 'A Price Target for U.S. Monetary Policy? Lessons from the Experience with Money Growth Targets,' Brookings Papers on Economic Activity, 1, pp. 77-146.

[17] Isard, Peter, Douglas Laxton, and Ann-Charlotte Eliasson, 1999, 'Simple Monetary Policy Rules Under Model Uncertainty,' manuscript prepared for the January 15-16, 1999 conference at the International Monetary Fund in celebration of the contributions of Robert Flood.

[18] Kerr, William and Robert King, 1996, 'Limits on Interest Rate Rules in the IS-LM Model' Federal Reserve Bank of Richmond Economic Quarterly, Spring.

[19] Kydland, Finn E., and Edward C. Prescott, 1977, 'Rules Rather Than Discretion: The Inconsistency of Optimal Plans,' Journal of Political Economy, vol. 85, no. 3, June, pages 473-91.

[20] Poole, William, 1970, 'Optimal Choice of Monetary Policy Instruments in a Simple Stochastic Macro Model,' Quarterly Journal of Economics, May, pp. 197-216.

[21] Rogoff, Kenneth, 1985, 'The Optimal Degree of Commitment to an Intermediate Monetary Target,' Quarterly Journal of Economics, 100, November, pp. 1169-1189.

[22] Rotemberg, Julio, and Michael Woodford, 1999, 'Interest-Rate Rules in an Estimated Sticky Price Model,' in Taylor (1999a).

[23] Sargent, Thomas J., 1999, The Conquest of American Inflation, Princeton University Press.

[24] Taylor, John B., 1999, 'An Historical Analysis of Monetary Policy Rules,' in John B. Taylor (1999a).

[25] Taylor, John B., 1999a, Monetary Policy Rules, University of Chicago Press, forthcoming. 
Response of Model to an Exogenous Monetary Policy Shock
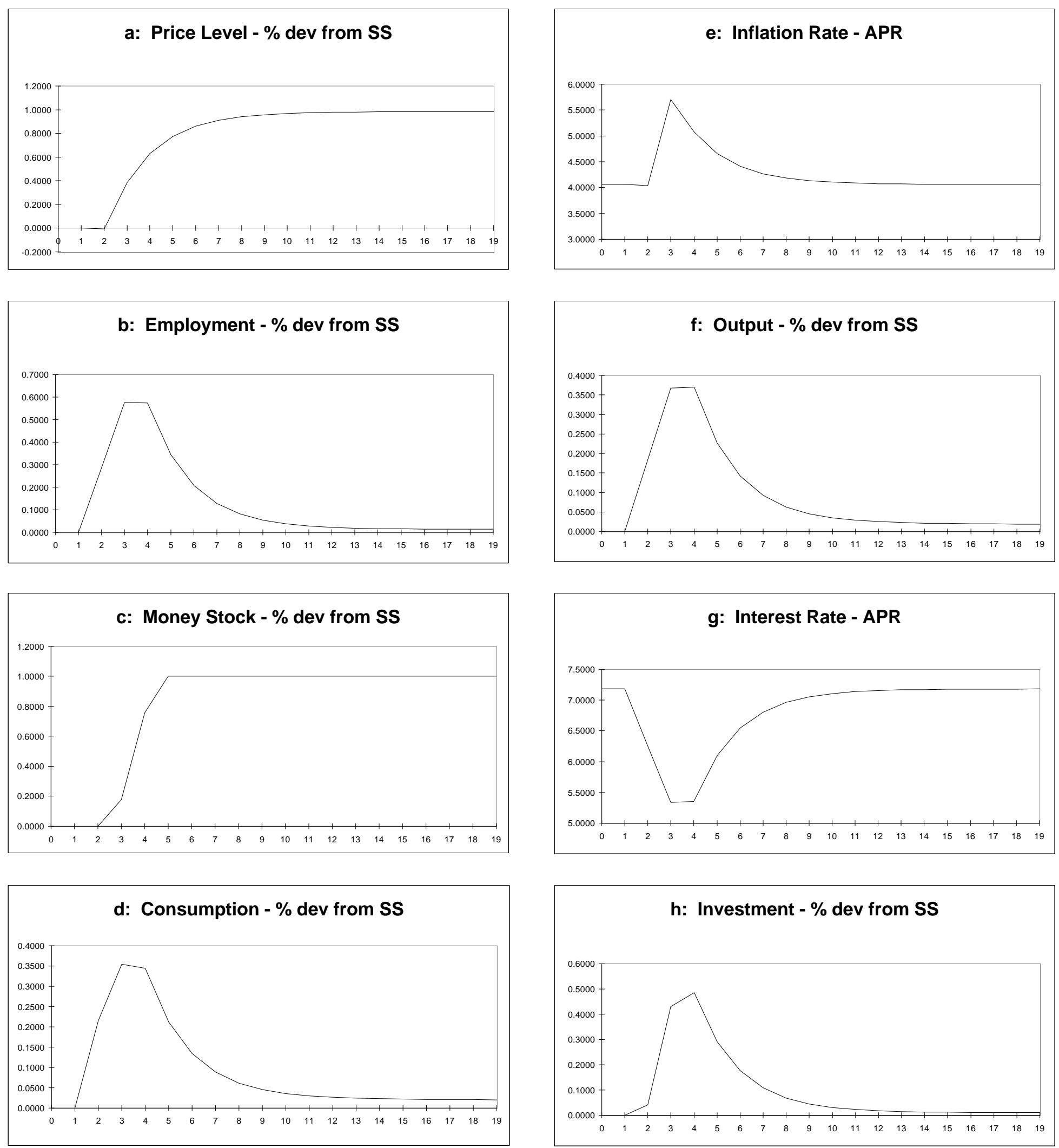

\% dev from SS: deviation from unshocked nonstochastic steady state growth path expressed in percent terms APR: annualized percentage rate 
Figure 2

Regions of Uniqueness, Explosiveness and Indeterminacy Clarida-Gali-Gertler Rule
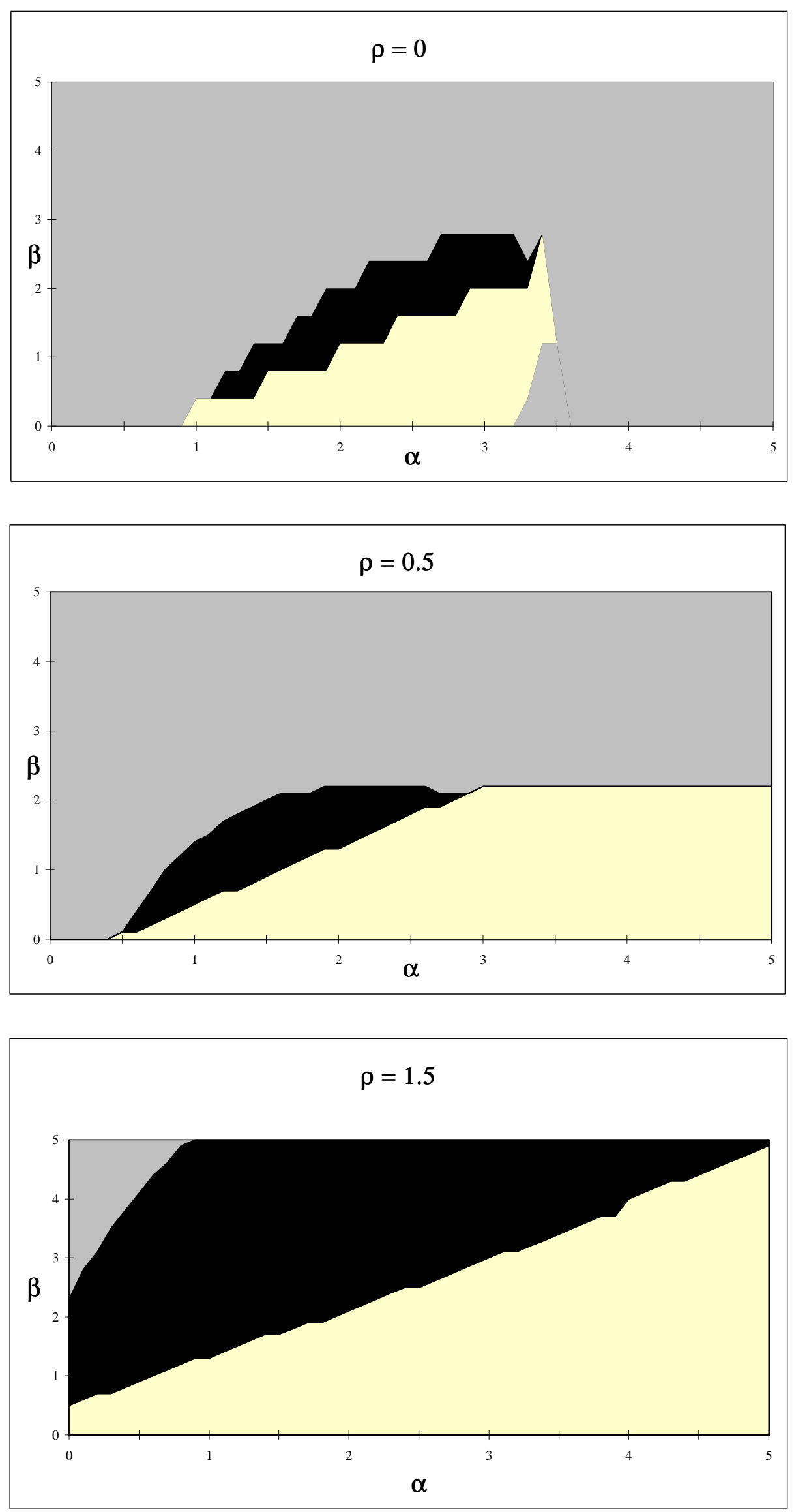

$\square$ Uniqueness 
Figure 3

Regions of Uniqueness, Explosiveness and Indeterminacy Generalized Taylor Rule
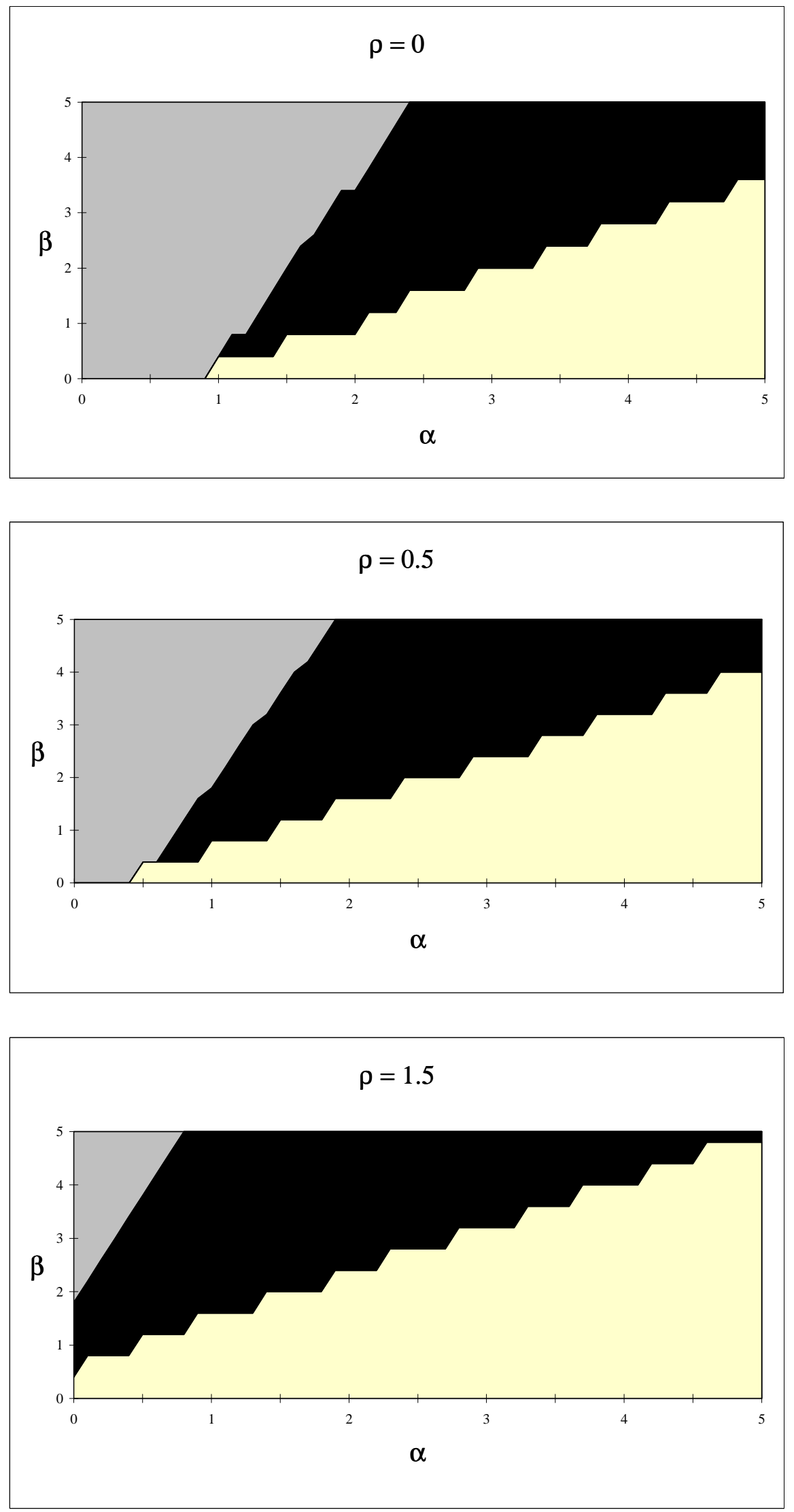

$\square$ Uniqueness 
Figure 4

Regions of Uniqueness, Explosiveness and Indeterminacy Lagged Taylor Rule
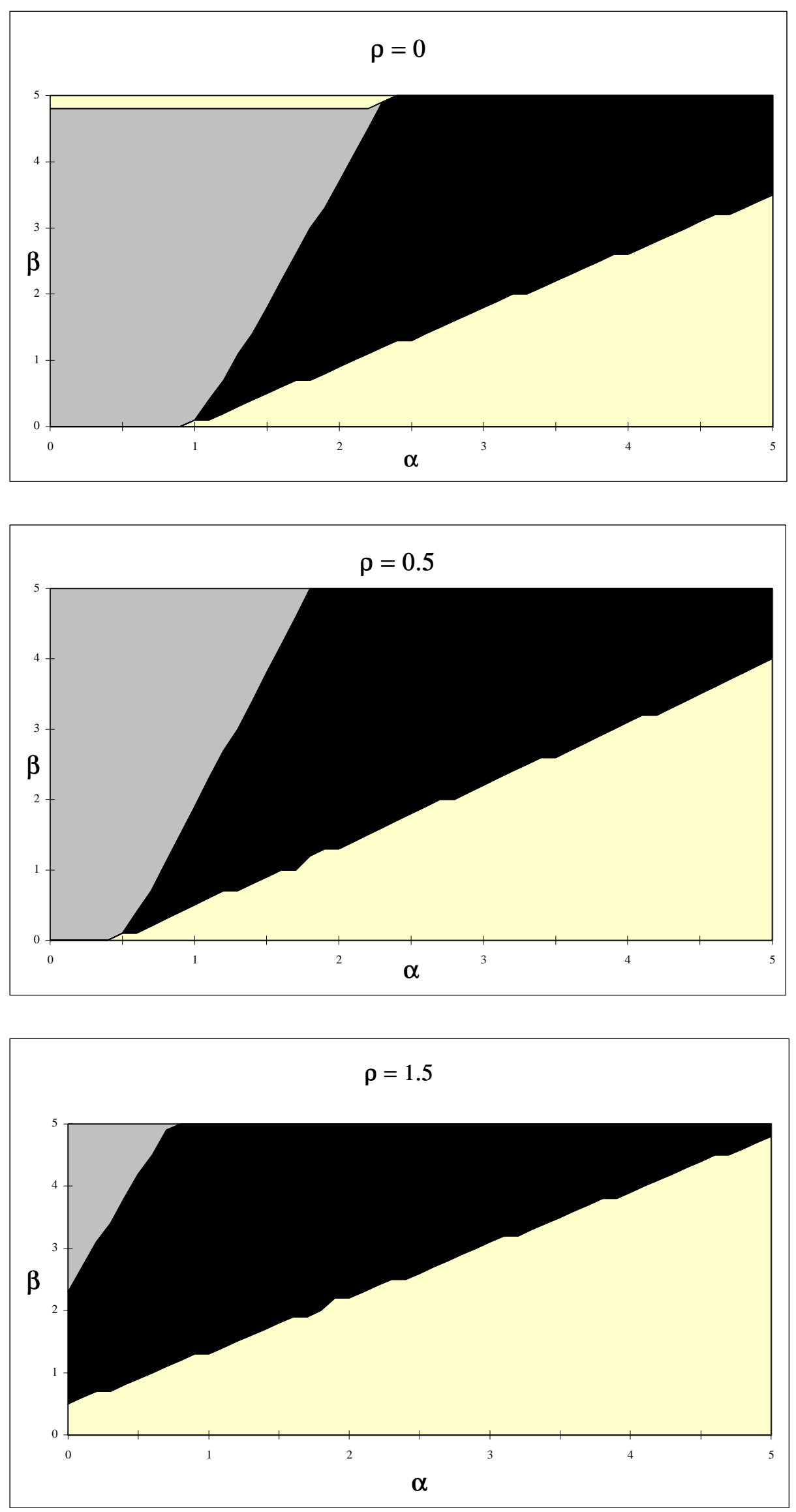

$\square$ Uniqueness 
Figure 5

Response to a Money Demand Shock Under Two Policy Rules
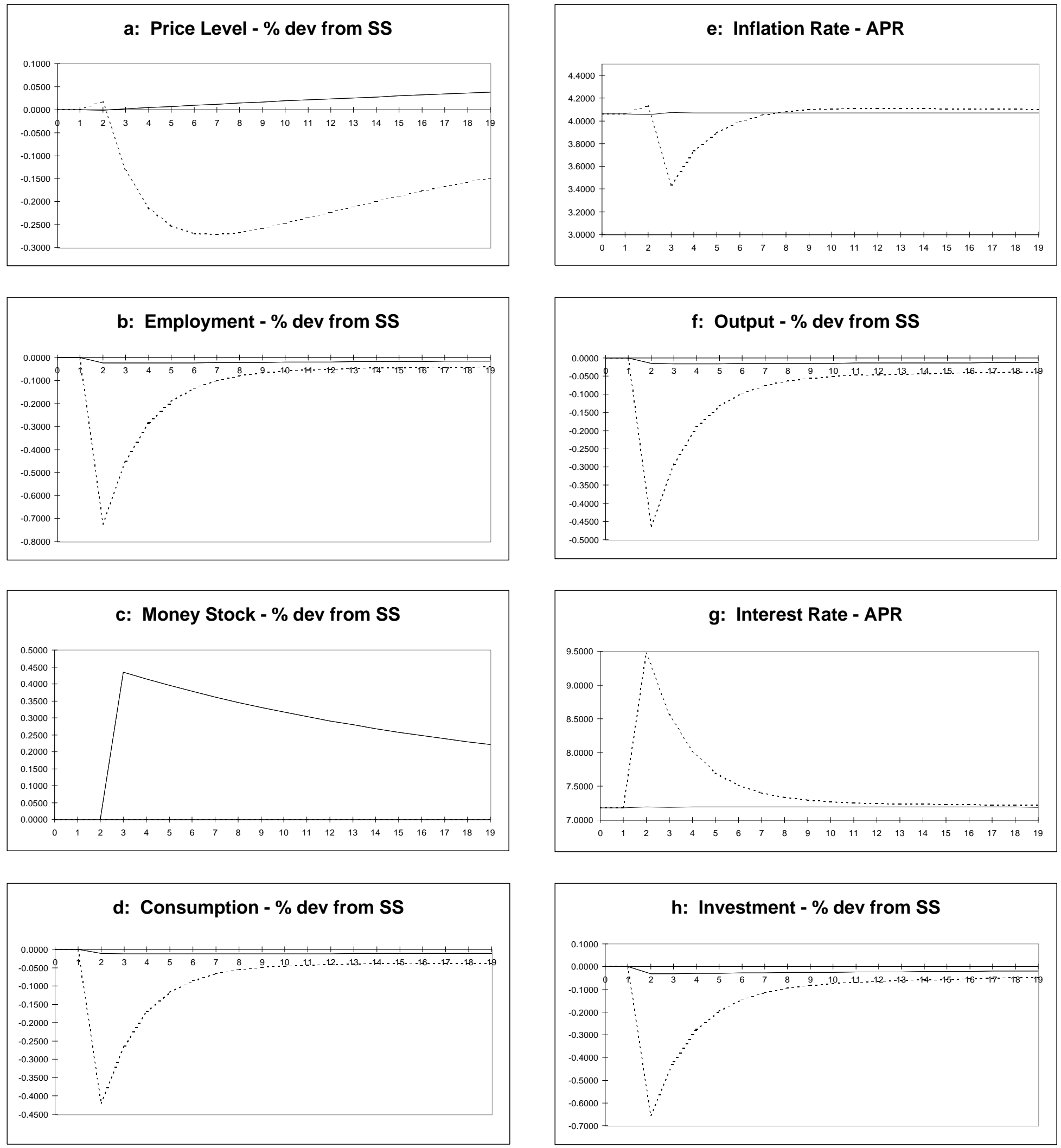

\section{Stable CGG Rule}

K\% Rule . . . . .

See Figure 1 for Notes 
Figure 6

Response to a Money Demand Shock Under Unstable CGG Rule
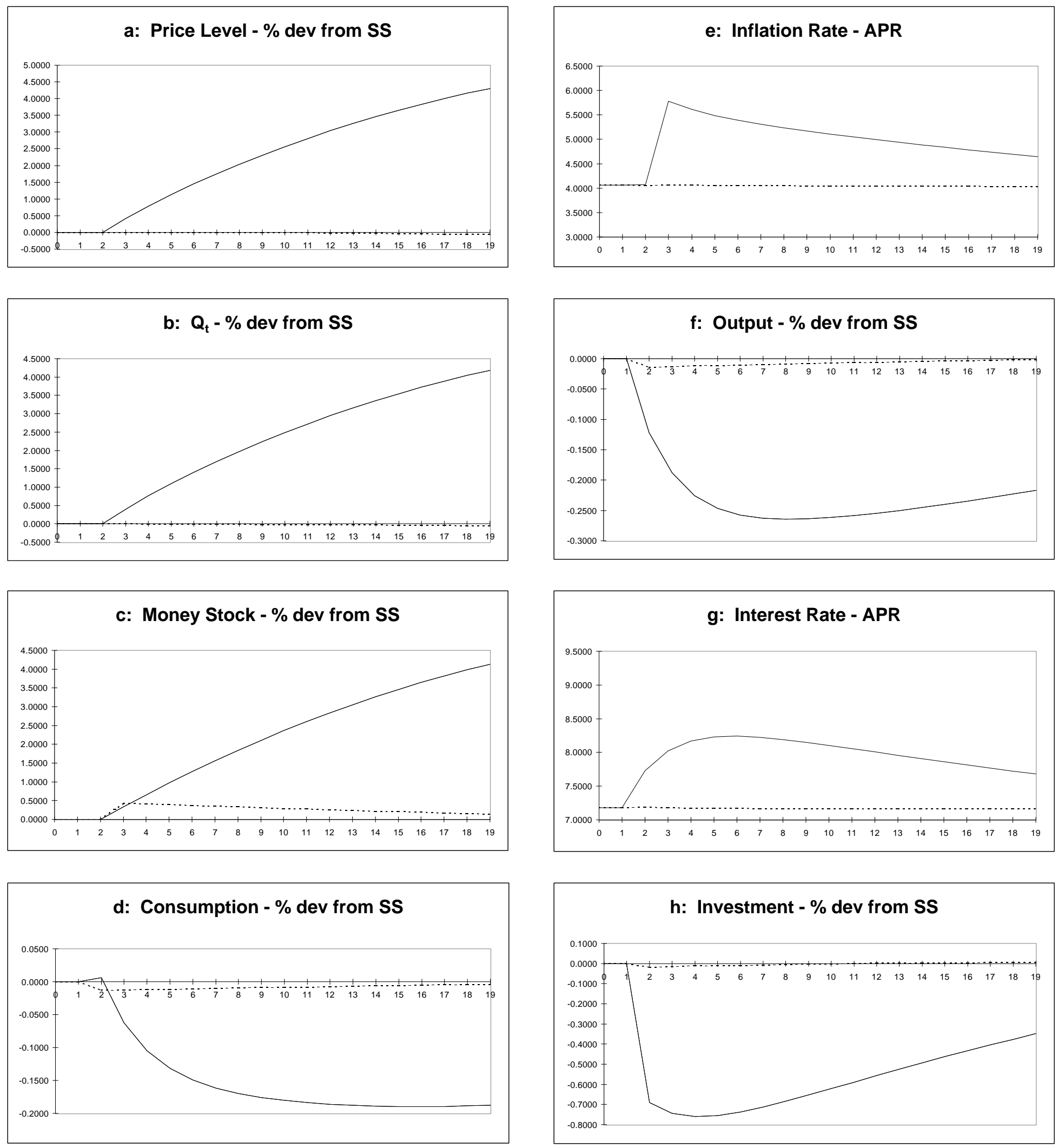

\section{Equilibrium 1}

Equilibrium 2 . . . . -

See Figure 1 for Notes 
Response to a Negative Technology Shock Under Two Policy Rules
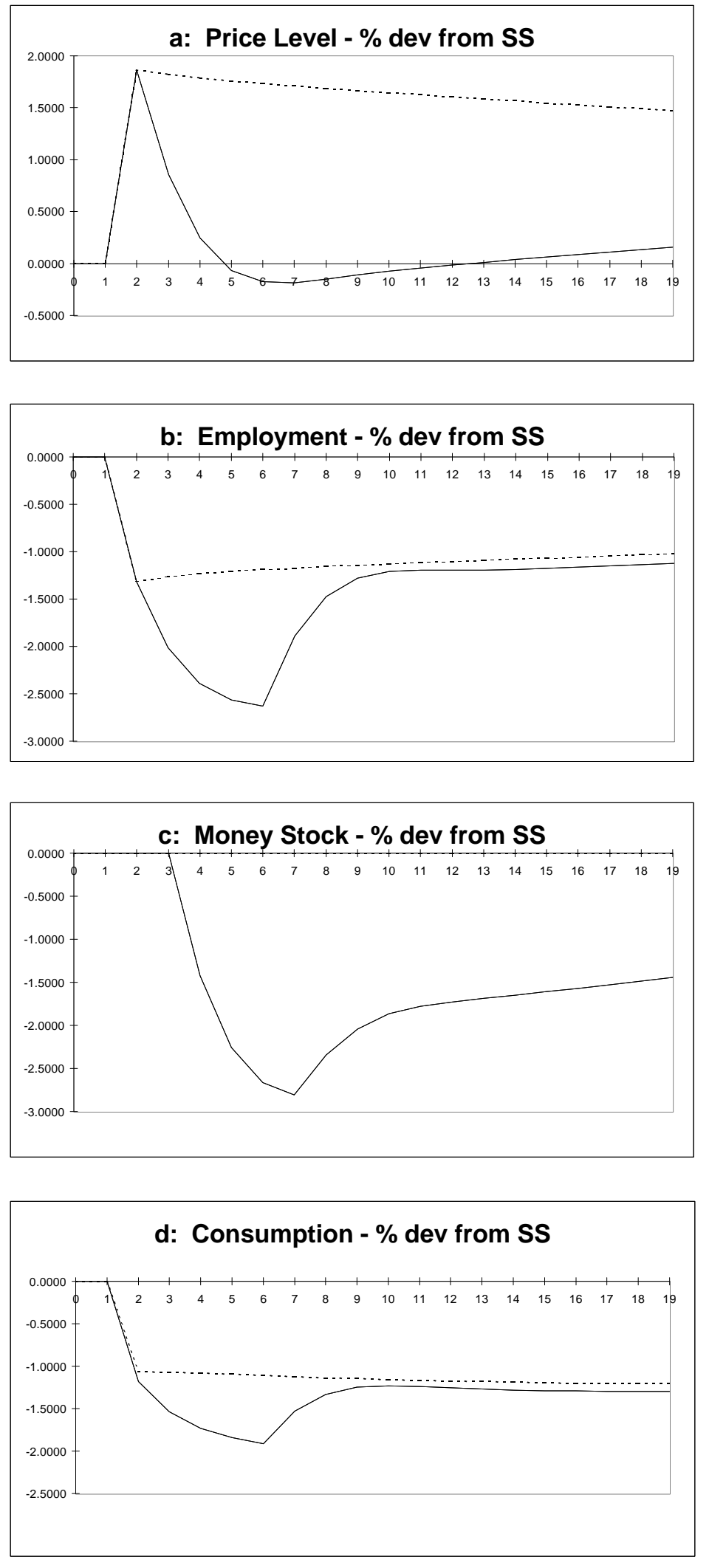

\section{RW Lagged Response Rule}

K\% Rule

See Figure 1 for Notes
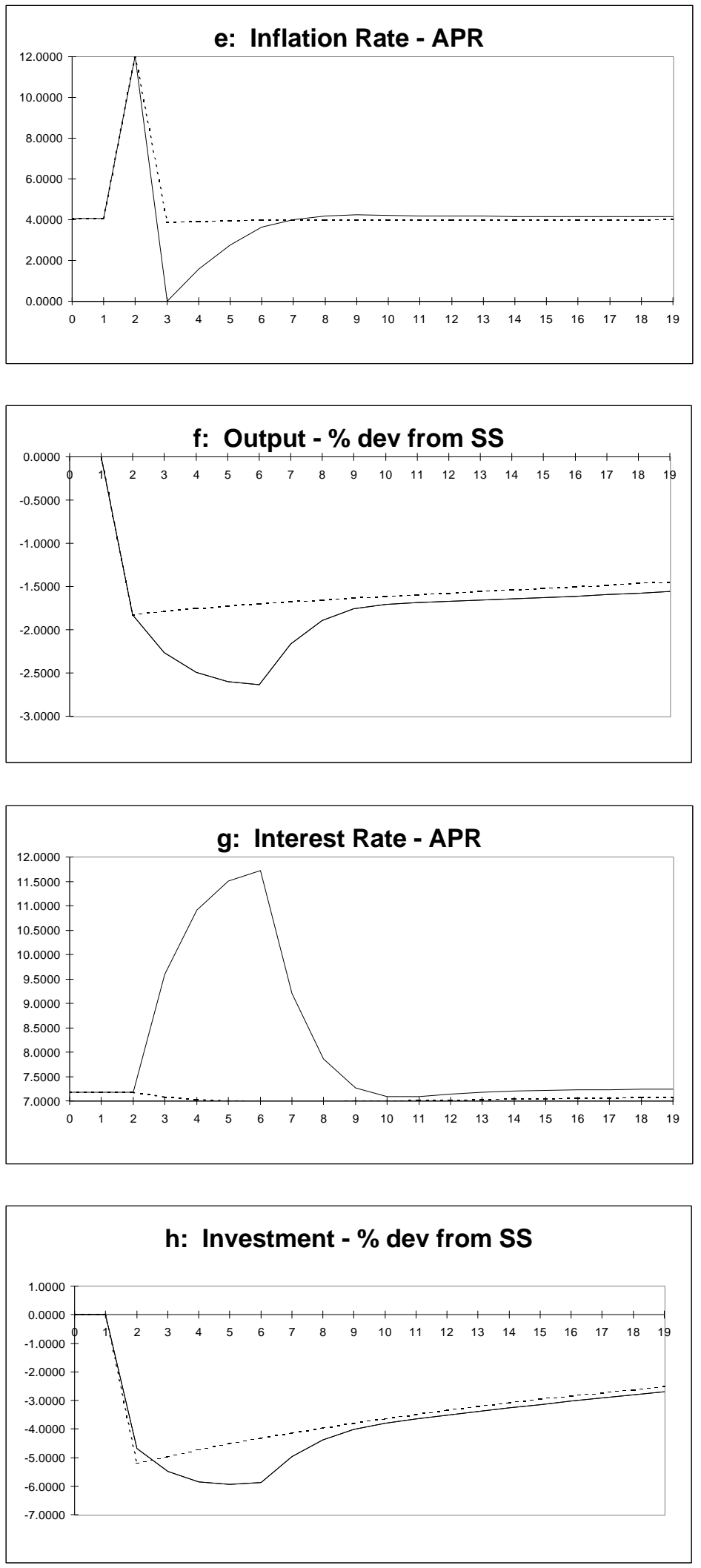
Response to a Negative Technology Shock Under Two Policy Rules

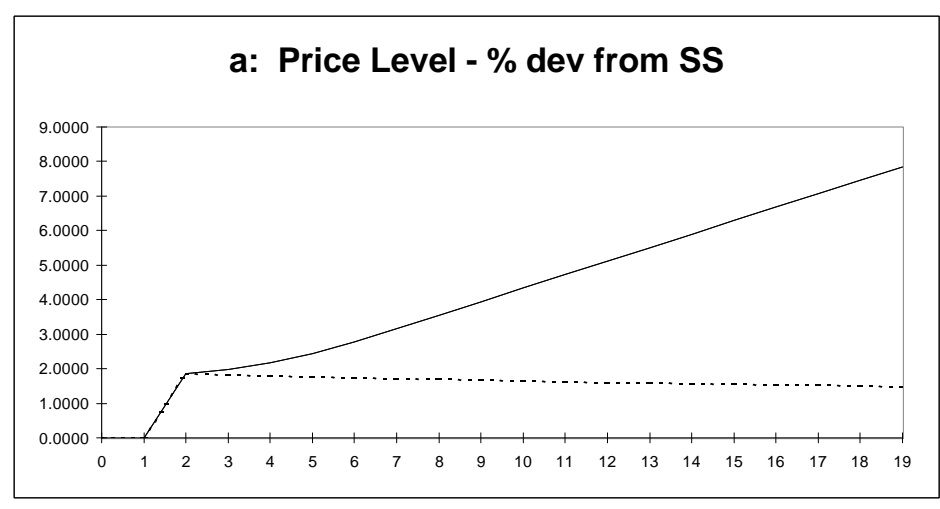

b: Employment - \% dev from SS

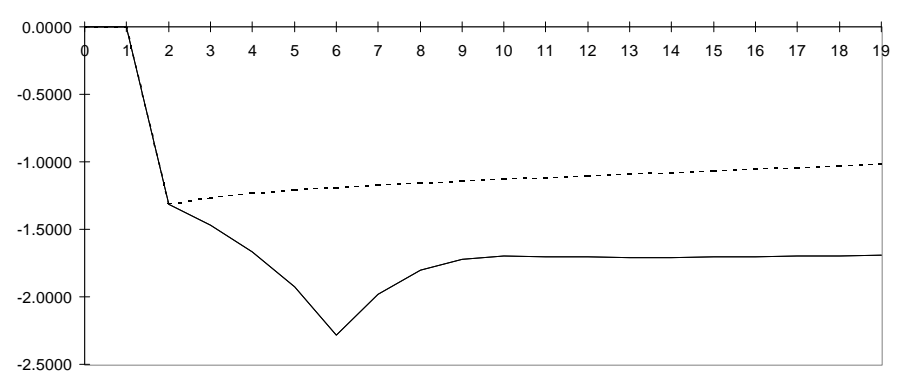

c: Money Stock - \% dev from SS

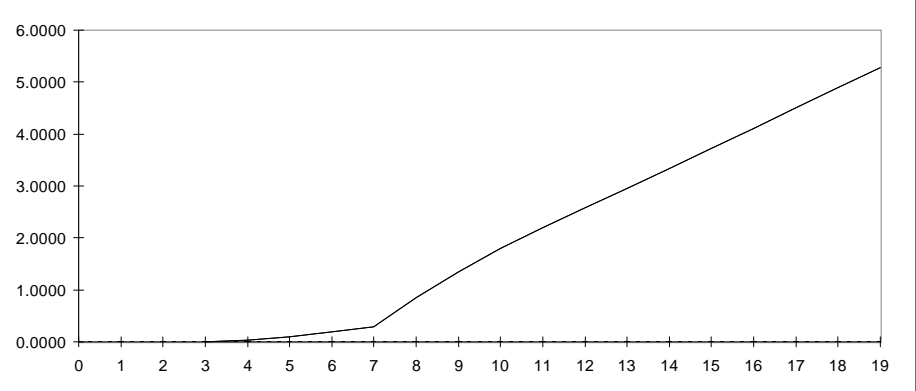

d: Consumption - \% dev from SS

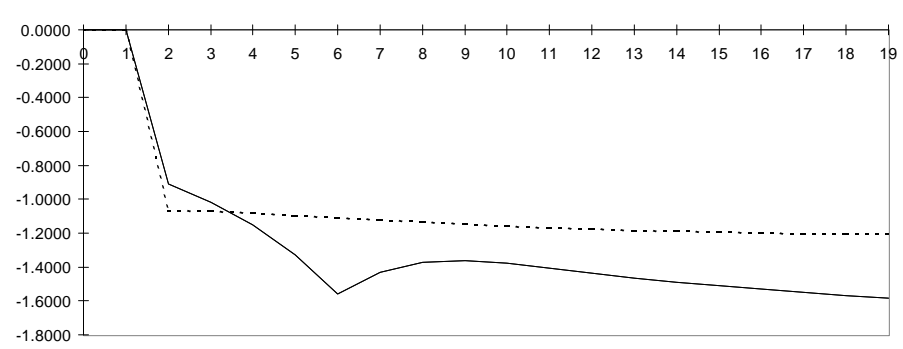

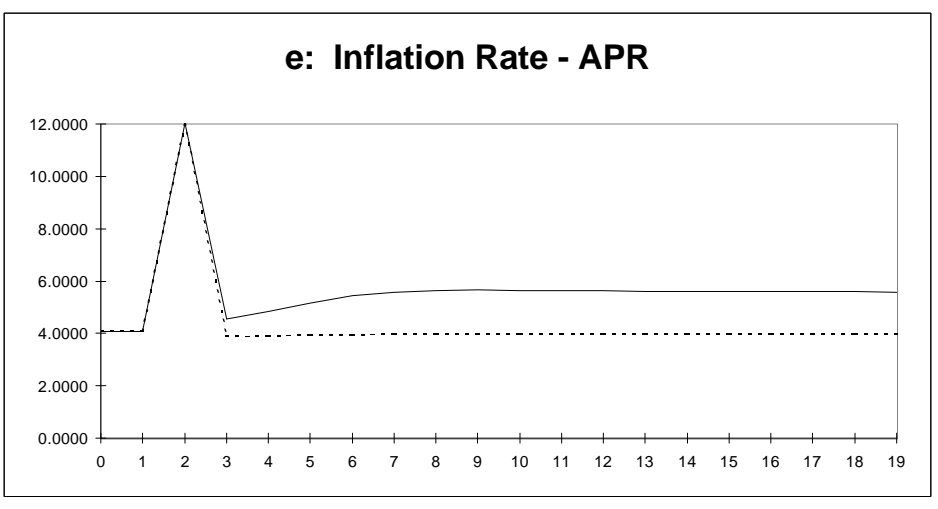
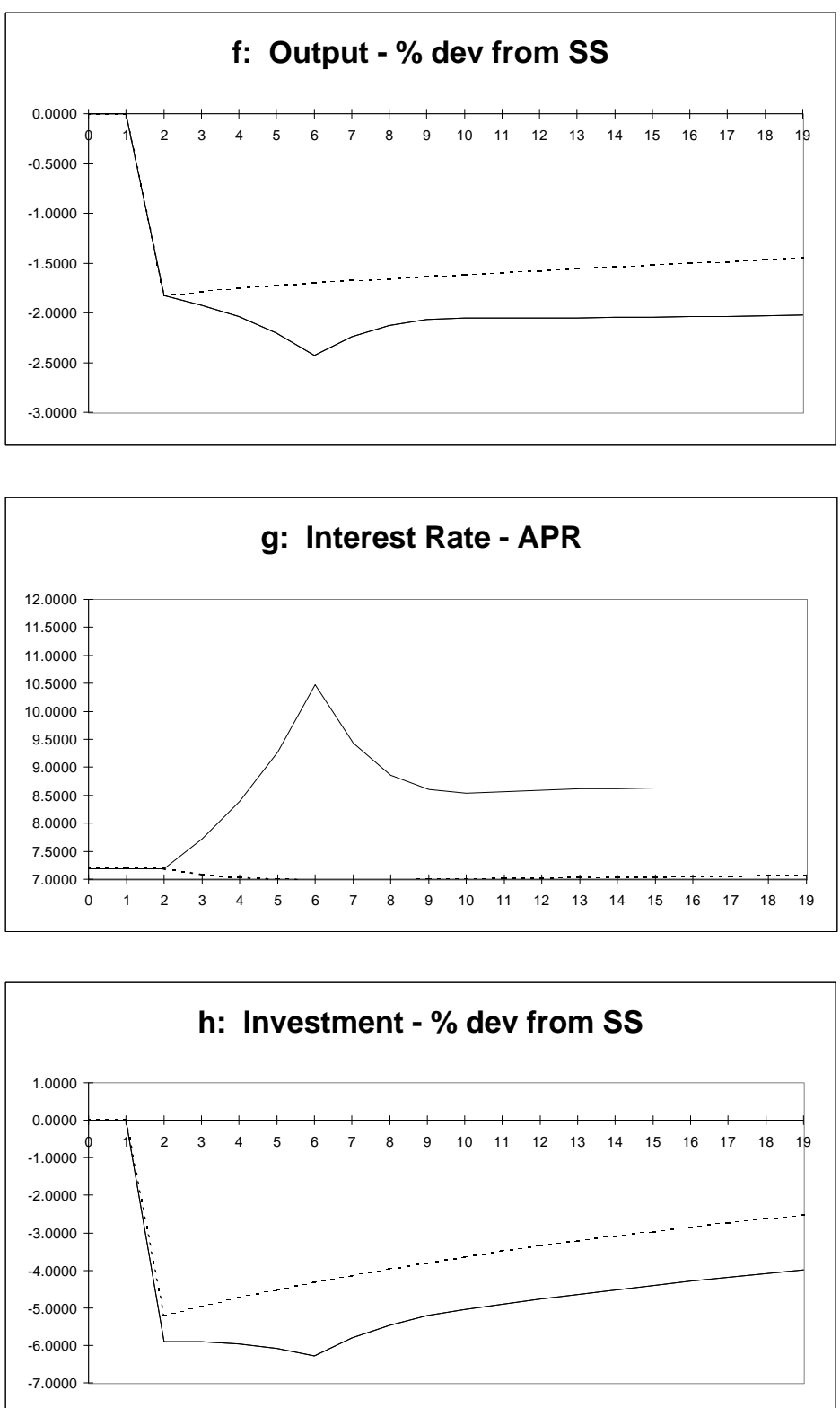

\section{Perturbed RW Lagged Response Rule}

\section{K\% Rule}

See Figure 1 for Notes 